\title{
Physiological studies on the role of cyanobacteria in ameliorating the toxic effects of copper in trigonella Foenum gracum
}

\author{
Basma M. Khalaf, Awatif A. Mohsen2, Samha M. Dowidar and Shaimaa Abo Hamad
}

Botany Department, Faculty of Science, Tanta University, Tanta, Egypt

\section{III}

Background: Cyanobacteria has been found to possess anti-toxic effects. Aim: To evaluate the ameliorating effects of Foenum gracum on the toxic effects of copper in a greenhouse experiment. Materials and Methods: The growth and some metabolic activities of Trigonella foenum gracum at 30, 60 days of growth was assessed after treatment with Nostoc muscorum $(2 \mathrm{~g} / \mathrm{kg}$ soil fresh pellets). The yield under different concentrations of $\mathrm{CuSO} 4$ was assessed. Results: Application of Nostoc in a mixture with $\mathrm{Cu}$ significantly increased all growth parameters, photosynthetic pigments and activity, soluble and insoluble nitrogen at 30 and 60 days of growth when compared with their counterparts of $\mathrm{Cu}$ treatment. In addition, the content of $\mathrm{K}+, \mathrm{Ca} 2+, \mathrm{P} 3+$ and iron were increased except for a decrease in $\mathrm{Cu}$ level at 60 days of growth. On the other hand, the content of starch and peptides were significantly decreased at 30 and 60 days of growth. Moreover, the activity of both POD and SOD were reduced by applying Nostoc to the soil having different concentrations of $\mathrm{Cu}$. Biochemical analysis of the yielded seeds of Trigonella revealed that the content of total carbohydrate, total soluble protein and total lipids were significantly increased, whereas total alkaloids and phenolics were significantly decreased. Mixing Nostoc with $\mathrm{Cu}$ increased the percentage of unsaturated fatty acids when compared with control and $\mathrm{Cu}$ singly. Scanning SDS-PAGE gel indicated de novo synthesis of two polypeptides with molecular weight of 44 and $67 \mathrm{KDa}$. Conclusion: Isozyme profile of POD and $\alpha$ and $\beta$-esterase of yielded seeds showed 3 isoforms of POD and $\alpha$ esterase and two isoforms of $\beta$-esterase varied in their intensity and thickening in response to different treatments.

Keywords: Amelioration; Biochemical changes; Copper; Nostoc muscorum; Trigonella foenum gracum 